Article

\title{
A Fast Ubiquitination of UHRF1 Oncogene Is a Unique Feature and a Common Mechanism of Thymoquinone in Cancer Cells
}

\author{
Mahmoud Alhosin 1,2,*D, Omeima Abdullah ${ }^{3}$, Asaad Kayali ${ }^{1}$ and Ziad Omran ${ }^{4, *}$ (D) \\ 1 Biochemistry Department, Faculty of Science, King Abdulaziz University, Jeddah 21589, Saudi Arabia; \\ akayali0001@stu.kau.edu.sa \\ 2 Centre for Artificial intelligence in Precision Medicines, King Abdulaziz University, \\ Jeddah 21589, Saudi Arabia \\ 3 College of Pharmacy, Umm Al-Qura University, Makkah 21955, Saudi Arabia; oaabdullah@uqu.edu.sa \\ 4 Pharmacy Program, Department of Pharmaceutical Sciences, Batterjee Medical College, \\ Jeddah 21442, Saudi Arabia \\ * Correspondence: malhaseen@kau.edu.sa (M.A.); ziad.omran@bmc.edu.sa (Z.O.)
}

check for

updates

Citation: Alhosin, M.; Abdullah, O.;

Kayali, A.; Omran, Z. A Fast

Ubiquitination of UHRF1 Oncogene

Is a Unique Feature and a Common

Mechanism of Thymoquinone in

Cancer Cells. Appl. Sci. 2021, 11, 7633.

https://doi.org/10.3390/

app11167633

Academic Editor: Przemysław

M. Płonka

Received: 15 July 2021

Accepted: 16 August 2021

Published: 19 August 2021

Publisher's Note: MDPI stays neutral with regard to jurisdictional claims in published maps and institutional affiliations.

Copyright: (c) 2021 by the authors. Licensee MDPI, Basel, Switzerland. This article is an open access article distributed under the terms and conditions of the Creative Commons Attribution (CC BY) license (https:// creativecommons.org/licenses/by/ $4.0 /$ )

\begin{abstract}
Downregulation of the ubiquitin-like containing PHD and ring finger 1 (UHRF1) oncogene in cancer cells in response to natural anticancer drugs, including thymoquinone (TQ), is a key event that induces apoptosis. TQ can induce UHRF1 autoubiquitination via the E3 ligase activity of its RING domain, most likely through the downregulation of herpes virus-associated ubiquitinspecific protease (HAUSP). In this study, we evaluated whether HAUSP downregulation and fast ubiquitination of UHRF1 are prerequisites for UHRF1 degradation in response to TQ in cancer cells and whether doxorubicin can mimic the effects of TQ on UHRF1 ubiquitination. RNA sequencing was performed to investigate differentially expressed genes in TQ-treated Jurkat cells. The protein expression of UHRF1, HAUSP and Bcl-2 was detected by means of Western blot analysis. The proliferation of human colon cancer (HCT-116) and Jurkat cells was analyzed via the WST-1 assay. RNA sequencing data revealed that TQ significantly decreased HAUSP expression. TQ triggered UHRF1 to undergo rapid ubiquitination as the first step in its degradation and the inhibition of its cell proliferation. TQ-induced UHRF1 ubiquitination is associated with HAUSP downregulation. Like TQ, doxorubicin induced a similar dose- and time-dependent downregulation of UHRF1 in cancer cells, but UHRF1 did not undergo ubiquitination as detected in response to TQ. Furthermore, TQ decreased Bcl-2 expression without triggering its ubiquitination. A fast UHRF1 ubiquitination is an indispensable event for its degradation in response to TQ but not for its responses to doxorubicin. TQ appears to trigger ubiquitination of UHRF1 but not of the Bcl-2 oncogene, thereby identifying UHRF1 as a specific target of TQ for cancer therapy.
\end{abstract}

Keywords: thymoquinone; UHRF1; ubiquitination; HAUSP; tumor suppressor genes

\section{Introduction}

The ubiquitin-like containing PHD and ring finger 1 (UHRF1) oncogene is overexpressed in many human cancers and serves as a master regulator of the epigenome (DNA methylation and histone modifications) through its five functional domains [1-7], including the RING domain, which is the only domain of UHRF1 that exhibits enzymatic activity $[2,8]$. Indeed, UHRF1 belongs to the ring finger-type E3-ubiquitin ligases, which have in vitro autoubiquitination activity [8-10] and are currently viewed as promising anticancer drug targets due to their roles in the regulation of many tumor suppressor proteins [8,11]. UHRF1 was shown to exert E3 ubiquitin ligase activity through its RING domain, whereas the overexpression of UHRF1 RING domain mutants enhanced the sensitivity of cancer cells to several genotoxic and cytotoxic agents [8].

The herpes virus-associated ubiquitin-specific protease (HAUSP) known as USP7 was shown to protect several RING-finger E3-ubiquitin ligases, such as Mdm2 [12], ICP0 [13], 
Chfr [14] and UHRF1, from autoubiquitination [15]. Indeed, HAUSP physically interacts with UHRF1 and an active HAUSP completely abolished the autoubiquitination of UHRF1 through the removal of ubiquitin adducts [15]. These findings indicate that HAUSP positively regulates the expression levels of UHRF1 through targeting the RING domainmediated autoubiquitination activity of UHRF1, preventing proteasomal degradation of UHRF1 [15]. These data, taken together, suggest that an intact function of the UHRF1 RING domain is essential for cellular survival and its disruption through the dissociation of HAUSP from the UHRF1 complex significantly enhances the sensitivity of cancer cells to chemotherapeutics, making UHRF1 a promising target in the search for natural compound to target in cancer therapy.

Several in vitro and in vivo studies have shown that UHRF1 downregulation in cancer is sufficient to induce apoptosis through the reactivation of various tumor suppressor genes (TSGs) [7,16-18]. Indeed, UHRF1 expression decreases in response to several natural products, including naphthazarin [19], shikonin [20], curcumin [5], epigallocatechin-3-gallate (EGCG) [4], resveratrol [21], anisomycin [21], luteolin [22], doxorubicin [23] and thymoquinone (TQ) $[1,11,24,25]$. TQ, the most abundant biologically active component of black seed oil, shows inhibitory effects on many human cancer cells by targeting several signaling pathways, including the UHRF1/TSGs axis $[1,7,11]$. TQ was shown to induce the rapid autoubiquitination of UHRF1 in cancer cells through its RING domain, and this event was correlated with HAUSP downregulation [11], which is known to control the ubiquitination status of UHRF1 and protects it from degradation by the proteasome [15]. These findings suggest that HAUSP downregulation-mediated rapid autoubiquitination of UHRF1 in response to TQ is an essential first step for subsequent UHRF1 degradation [11]. In the present study, we evaluated whether TQ specifically triggers HUASP downregulationmediated fast ubiquitination of UHRF1 in cancer cells and whether the anticancer drug doxorubicin, which is known to decrease the expression of the UHRF1 protein through an unknown mechanism [23], can mimic the effects of TQ on UHRF1.

\section{Materials and Methods}

\subsection{Cell Culture and Treatment}

The human T lymphocyte Jurkat cell line and human colon cancer cells (HCT-116) were obtained from the American Type Culture Collection (Manassas, VA, USA) and maintained in a humidified incubator at $37^{\circ} \mathrm{C}$ in $5 \% \mathrm{CO}_{2}$. Jurkat cells were grown in RPMI 1640 culture medium (Sigma-Aldrich, St-Louis, MO, USA) and HCT-116 cells in Dulbecco's modified Eagle medium (DMEM) (Sigma-Aldrich, St-Louis, MO, USA). All media were supplemented with 15\% ( $v / v)$ fetal calf serum (FCS; Biowhitaker, Lonza, Belgium), $2 \mathrm{mM}$ glutamine, $100 \mathrm{U} / \mathrm{mL}$ penicillin and $50 \mu \mathrm{g} / \mathrm{mL}$ streptomycin (Sigma, St. Louis, MO, USA). For all treatments, a $10 \mathrm{mM}$ solution of TQ (Sigma-Aldrich, St. Louis, MO, USA) was prepared in 10\% DMSO (dimethylsulfoxide; Millipore, Molsheim, France) and appropriate working concentrations were prepared with cell culture medium. The final concentration of DMSO was always less than $0.1 \%$ in both control and treated conditions. Doxorubicin was obtained from Sigma-Aldrich.

\subsection{RNA-Seq, Identification of Differentially Expressed Genes and Bioinformatics Analysis}

Triplicate samples of Jurkat cells were treated with $20 \mu \mathrm{M}$ TQ for $24 \mathrm{~h}$, and three independent experiments were performed. The total RNA was extracted using the RNeasy kit Qiagen (Valencia, CA, USA). RNA-Seq and the determination of differentially expressed genes were carried out as described elsewhere [6].

\subsection{Western Blot Analysis}

Cells were treated with different concentrations of TQ or doxorubicin for different times. The cells were then harvested, centrifuged to discard the medium, washed with cold PBS (phosphate-buffered saline), and resuspended in RIPA buffer ( $25 \mathrm{mM}$ Tris, $\mathrm{pH}$ 7.6, $150 \mathrm{mM} \mathrm{NaCl}, 1 \% \mathrm{NP}-40,1 \%$ sodium deoxycholate and 0.1\% SDS; Sigma-Aldrich, USA) 
containing protease inhibitors. Equal amounts of total protein were separated on 10-12\% polyacrylamide gels and electrophoretically transferred to nitrocellulose membranes. After blocking with $5 \%$ non-fat dry milk or 3\% bovine serum albumin (BSA) and Tween 20 in PBS, the nitrocellulose membranes were incubated at $4{ }^{\circ} \mathrm{C}$ overnight with either a mouse monoclonal anti-UHRF1 antibody [26], a mouse monoclonal anti-HAUSP antibody (Santa Cruz Biotechnology, Dallas, TX, USA, Cat. No. sc-137008), a mouse monoclonal anti-Bcl-2 (Cat. No. ab59348), or a mouse monoclonal anti-GAPDH (Cat. No. ab8245) or an anti$\beta$-actin antibody (Cat. No. ab8226) (Abcam, Paris, France) or $\beta$-tubulin (Sigma-Aldrich, Cat. No. T8328), according to the manufacturer's instructions. The membranes were then washed three times with PBS for $10 \mathrm{~min}$, followed by incubation with an appropriate horseradish peroxidase-conjugated secondary antibody (diluted to 1:10,000 for anti-mouse antibodies) at room temperature for $90 \mathrm{~min}$. The membranes were washed with PBS five times, and the chemiluminescence signals were detected using Amersham ECL Plus detection system (Amersham, GE Healthcare, Buckinghamshire, UK).

\subsection{Cell Proliferation Assay}

A colorimetric cell proliferation assay using a WST-1 Cell Proliferation Reagent Kit (Sigma-Aldrich, USA) was used to analyze the effect of TQ on cell proliferation in HCT116 and Jurkat cells. Briefly, the cells were seeded in 96-multiwell plates at a density of $4 \times 10^{4} /$ well for Jurkat cells and $10^{4} /$ well for HCT-116 cells. After $24 \mathrm{~h}$ of incubation, the cells were exposed to different concentrations of TQ for different times. The cell proliferation rate then was evaluated through a rapid WST-1 reagent. After incubation for the different times, $10 \mu \mathrm{L}$ of the WST-1 solution was added and incubated for an additional $3 \mathrm{~h}$ at $37^{\circ} \mathrm{C}$. Finally, the absorbance was read at $450 \mathrm{~nm}$ with a microplate ELISA reader (ELx800 ${ }^{\mathrm{TM}}$ Biotek, Winooski, Vermont, USA) and the results were analyzed using the Gen5 software (Biotek, Winooski, VT, USA). The reaction was based on the cleavage of the tetrazolium salt WST-1 to formazan by means of cellular mitochondrial dehydrogenases. The quantity of formazan dye in the medium is directly proportional to the number of viable metabolically active cells. The percentage of cell viability was calculated by assuming control (untreated) samples to be $100 \%$ viable.

\subsection{Statistical Analysis}

All the data were presented as the means \pm S.E.M of triplicates carried out in the same experiment or an average of at least three separate experiments. One-way ANOVA, followed by Tukey's post hoc test using GraphPad Prism 6 (Graph Pad Software, SanDiego, CA, USA), were used for statistical analysis. Significant differences are indicated as $* p<0.05$.

\section{Results}

\subsection{TQ Induced UHRF1 Ubiquitination Related to HAUSP Downregulation in Human Cancer Cells}

The HAUSP deubiquitinase interacts with the UHRF1 protein and controls its ubiquitination status, thereby protecting UHRF1 from degradation by the proteasome [15,27]. TQ was shown to induce a sharp decrease in HAUSP in Jurkat cells [11]. We therefore investigated whether HAUSP is a main target of TQ in its mechanism of action leading to UHRF1 downregulation by analyzing gene expression after a 24-h exposure to TQ. The RNA-seq data showed that several deubiquitinases, including HAUSP, with known oncogenic proprieties were significantly downregulated in response to TQ treatment (Table 1). By contrast, two deubiquitinases, USP27X and USP35, which are known tumor suppressors, were insignificantly upregulated (Table 2).

We then investigated whether UHRF1 ubiquitination is a common feature of TQ in cancer cells and whether this process involves the downregulation of HAUSP by evaluating the effects of TQ in two human cancer cell lines that highly express UHRF1: human colon cancer cells (HCT-116) [28,29] and Jurkat cells [1,30,31]. TQ induced a sharp decrease in the expression of UHRF1 and HAUSP at the protein level when administered at 
concentrations of at least $200 \mu \mathrm{M}$ in HCT-116 cells (Figure 1A) and $30 \mu \mathrm{M}$ in Jurkat cells (Figure 1B). The anti-proliferative effect of TQ in HCT-116 cells (Figure 1C) and in Jurkat cells (Figure 1D) was then analyzed under the same experimental conditions. Cell proliferation in response to TQ was decreased in a concentration-dependent manner in both cancer cell lines. TQ significantly inhibited cell proliferation starting from $30 \mu \mathrm{M}$ in HCT-116 cells and the inhibition percentage reached approximately $50 \%$ at $100 \mu \mathrm{M}$, suggesting that TQ exerts its inhibitory effects on HCT-116 cells with an estimated half-maximal effect (IC50) value of approximately $100 \mu \mathrm{M}$ (Figure 1C). In Jurkat cells, TQ significantly inhibited cell proliferation from $5 \mu \mathrm{M}$, with an IC50 value of approximately $30 \mu \mathrm{M}$ (Figure 1D).

Table 1. Downregulation of deubiquitinases in TQ-treated Jurkat cells as compared with untreated cells.

\begin{tabular}{ccc}
\hline Gene & $\operatorname{logFc}^{*}$ & $p$-Value \\
\hline USP4 & -1.065 & 0.026 \\
\hline USP7 & -0.907 & 0.05 \\
\hline USP8 & -1.003 & 0.037 \\
\hline USP12 & -1.067 & 0.0283 \\
\hline USP15 & -1.19 & 0.012 \\
\hline USP24 & -1.566 & 0.001 \\
\hline USP32 & -1.239 & 0.01 \\
\hline USP34 & -1.9 & 0.0000398
\end{tabular}

Table 2. Upregulation of deubiquitinases in TQ-treated Jurkat cells as compared with untreated cells.

\begin{tabular}{ccc}
\hline Gene & $\operatorname{logFc} c^{*}$ & $p$-Value \\
\hline USP27 & 0.207 & 0.84 \\
\hline USP35 & 0.49 & 0.34 \\
\hline
\end{tabular}

A kinetic analysis of the effects of TQ on UHRF1 expression, using concentrations at which UHRF1 became undetectable, $200 \mu \mathrm{M}$ of TQ in HCT-116 cells (Figure 2A) and $30 \mu \mathrm{M}$ in Jurkat cells (Figure 2B), revealed time-dependent effects of TQ on UHRF1 ubiquitination, as reflected by the appearance of high-molecular-weight bands of UHRF1 at 115 and $250 \mathrm{kDa}$, rather than the expected one at $97 \mathrm{kDa}$. The TQ-induced UHRF1 ubiquitination was associated with a decrease in the expression of HAUSP, detectable at $10 \mathrm{~min}$ in HCT116 cells (Figure 2A) and Jurkat cells (Figure 2B) in parallel with the appearance of highmolecular-weight bands on UHRF1. The TQ-induced downregulation of UHRF1 and HAUSP was also associated with an upregulation of the p73 tumor suppressor protein in both cancer cell lines (data not shown). The anti-proliferative effect of TQ in HCT-116 cells (Figure 2C) and Jurkat cells (Figure 2D) was also analyzed under the same experimental conditions. TQ induced a time-dependent cell proliferation inhibition in HCT-116 cells (Figure 2C) and Jurkat cells (Figure 2D) and this effect was associated with the TQ-induced UHRF1 ubiquitination. Indeed, TQ caused a significant decrease in cell proliferation after $1 \mathrm{~h}$ and $30 \mathrm{~min}$ in HCT-116 cells (Figure 2C) and Jurkat cells (Figure 2D), respectively. 
A

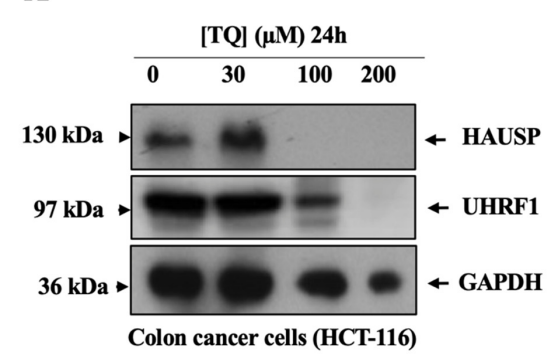

C

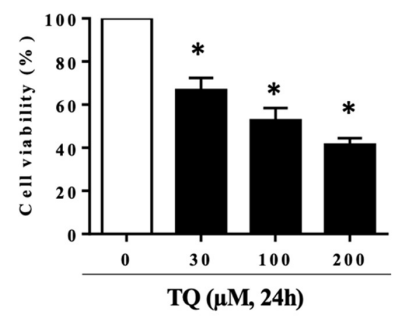

B

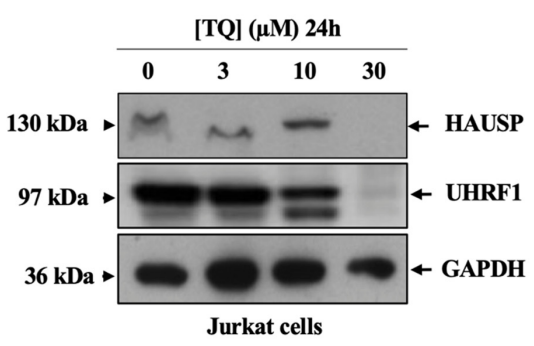

D

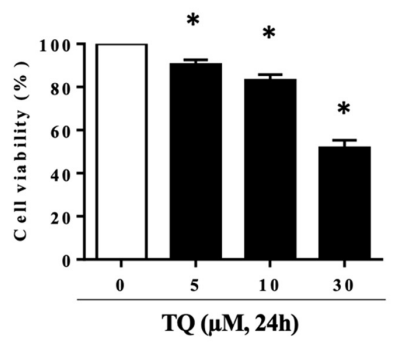

Figure 1. Dose-dependent effect of TQ on the protein expression of HAUSP and UHRF1 and cell proliferation. Human colon cancer (HCT-116) (A,C) and Jurkat cells (B,D) were exposed to increasing concentrations of TQ for $24 \mathrm{~h}$. The expression of HAUSP and UHRF1 was analyzed by means of Western blotting, as described in the Materials and Methods. The cell proliferation rate was assessed via the WST-1 assay. Values are shown as means \pm S.E.M of three different experiments. * $p<0.05$ versus control.

A

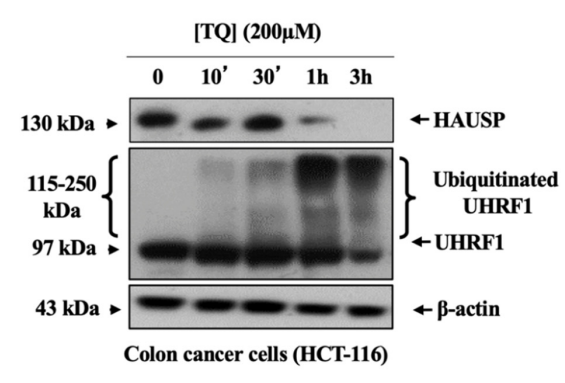

C

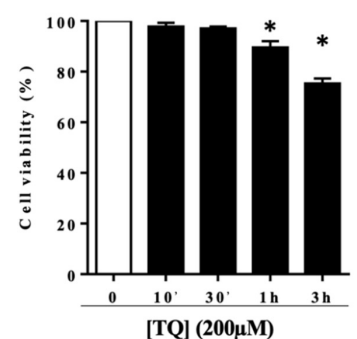

B

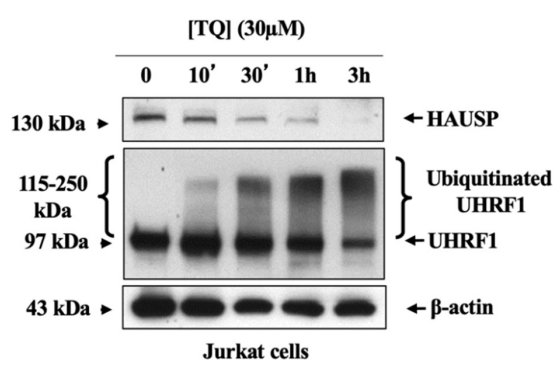

B

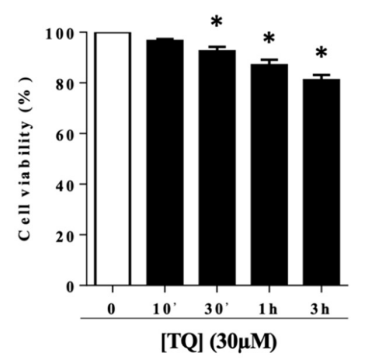

Figure 2. Time course effect of TQ on HAUSP, UHRF1 and ubiquitinated UHRF1 and cell proliferation. Human colon cancer cells (HCT-116) (A,C) and Jurkat cells (B,D) were exposed to $200 \mu \mathrm{M}$ and $30 \mu \mathrm{M}$ TQ, respectively, for different times. The expression of HAUSP and UHRF1 was analyzed by means of Western blotting, as described in the Materials and Methods. The cell proliferation rate was assessed via the WST-1 assay. Values are shown as means \pm S.E.M of three different experiments. ${ }^{*} p<0.05$ versus control. 
Taken together, these findings indicate that TQ induces a fast ubiquitination of UHRF1 in cancer cells that is related to HAUSP downregulation. This process could be an indispensable event in the subsequent degradation of UHRF1 and the upregulation of the p73 tumor suppressor and the inhibition of cell proliferation in response to TQ.

\subsection{Doxorubicin Induced Ubiquitination Independently of UHRF1 Downregulation in Cancer Cells}

The anticancer drug doxorubicin is commonly considered to exert its anti-tumor activity through targeting several signaling pathways, including the induction of the polyubiquitination of various proteins [32-34]. Doxorubicin was shown to decrease the expression of the UHRF1 protein in HCT-116 cells through an unknown mechanism [23]. Thus, we wanted to know whether doxorubicin induces a rapid ubiquitination of UHRF1 in cancer cells, thereby mimicking the effects of TQ on the ubiquitination status of UHRF1. As shown in Figure 3A, treatment of Jurkat cells with doxorubicin resulted in a dosedependent decrease in the expression protein level of UHRF1 starting at doxorubicin concentrations of $0.25 \mu \mathrm{g} / \mathrm{mL}$. A kinetic analysis of UHRF1 expression in Jurkat cells was then conducted using doxorubicin at $2 \mu \mathrm{g} / \mathrm{mL}$, a concentration at which UHRF1 became undetectable after $24 \mathrm{~h}$ of treatment (Figure 3A). A time-course analysis showed that doxorubicin induced a sharp decrease in the expression of UHRF1 at $6 \mathrm{~h}$ (Figure 3B). However, although TQ at 10 min induced UHRF1 ubiquitination, as reflected by the rapid appearance of high-molecular-weight bands of UHRF1 (Figure 3C), Western blot analysis revealed that doxorubicin treatment did not challenge UHRF1 to perform ubiquitination before the onset of its degradation in Jurkat cells (Figure 3B).
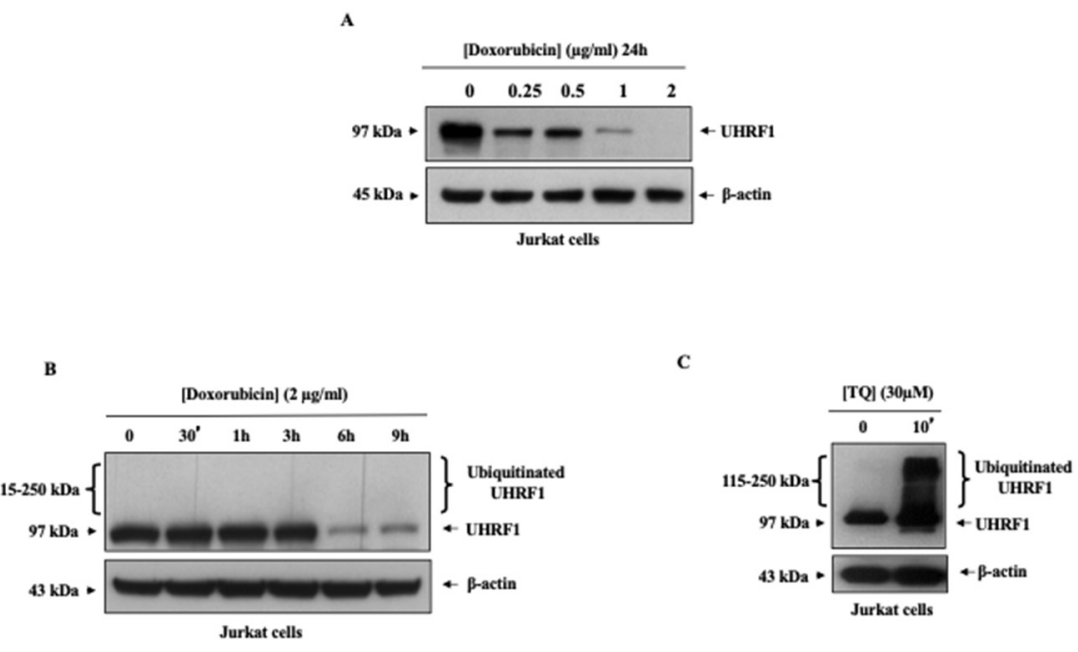

Figure 3. Dose- and time-dependent effects of doxorubicin and TQ on the protein expression of UHRF1 and ubiquitinated UHRF1 in Jurkat cells. (A) Jurkat cells were exposed to increasing concentrations of doxorubicin for $24 \mathrm{~h}$. (B) Cells were exposed to $2 \mu \mathrm{g} / \mathrm{mL}$ doxorubicin for different times. (C) Cells were exposed to $30 \mu \mathrm{M} \mathrm{TQ}$ for $10 \mathrm{~min}$. Expression of UHRF1 was analyzed via Western blotting, as described in the Materials and Methods.

The same findings were observed in HCT-116 cells treated with doxorubicin (Figure 4). Figure 4A shows that the treatment of colon cancer cells with doxorubicin resulted in a dosedependent decrease in the protein expression level of UHRF1, with concentrations as low as $10 \mu \mathrm{g} / \mathrm{mL}$. The time-course effects of $60 \mu \mathrm{g} / \mathrm{mL}$ of doxorubicin on UHRF1 expression showed a decrease in the expression of UHRF1 starting at $6 \mathrm{~h}$ (Figure 4B). Again, the doxorubicin-induced UHRF1 downregulation was not correlated with the ubiquitination process, as reflected by the lack of high-molecular-weight bands of UHRF1 (Figure 4B), as was observed in response to TQ (Figure 4C). 
A

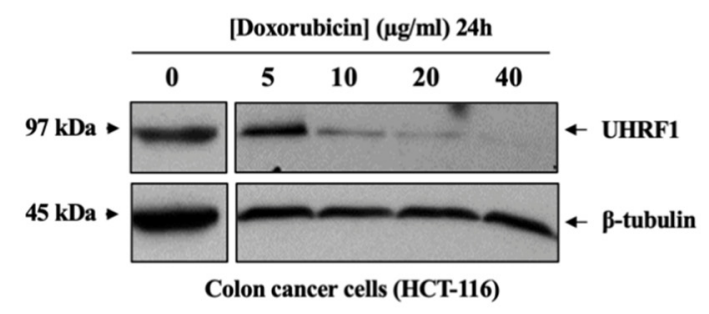

B

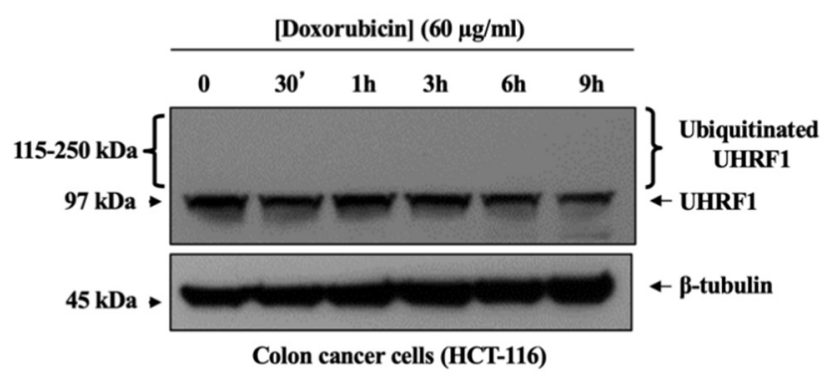

C

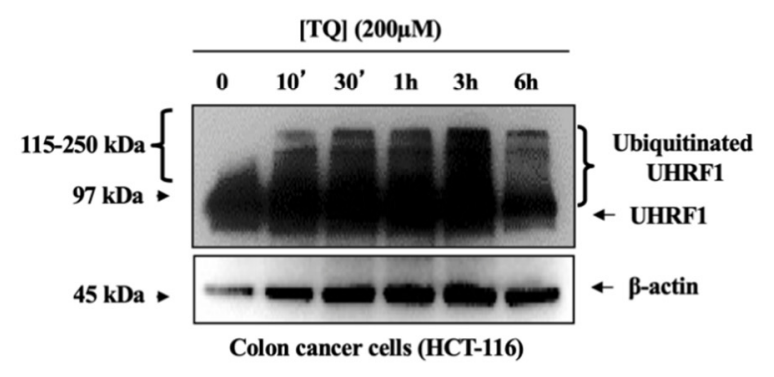

Figure 4. Dose- and time-dependent effects of doxorubicin or TQ on the protein expression of UHRF1 and ubiquitinated UHRF1 in colon cancer cells. (A) HCT-116 cells were exposed to increasing concentrations of doxorubicin for $24 \mathrm{~h}$. (B) Cells were exposed to $60 \mu \mathrm{g} / \mathrm{mL}$ doxorubicin for different times. (C) Cells were exposed to $200 \mu \mathrm{M}$ TQ for different times. Expression of UHRF1 was analyzed via Western blotting, as described in the Materials and Methods.

Taken together, these finding suggest that TQ and doxorubicin decreased UHRF1 protein expression through different mechanisms and indicate that fast UHRF1 ubiquitination is a prerequisite for its degradation in cancer cells in response to TQ but not for the response to doxorubicin.

\subsection{TQ Induced the Downregulation of the Bcl-2 Oncogene in Cancer Cells through a Ubiquitination-Independent Mechanism}

The B-cell lymphoma 2 (Bcl-2) oncogene is overexpressed in several tumors, including colon cancer [35-38] and Jurkat cells [39-41]. Bcl-2 was shown to be degraded in the proteasome through a ubiquitination pathway in response to several signals [42,43]. We investigated whether Bcl-2, like UHRF1, also underwent fast ubiquitination before its degradation in response to TQ in colon cancer cells and Jurkat cells. Dosage analysis of TQ on the expression of Bcl-2 in both cancer cell lines revealed that the treatment of HCT-116 cells (Figure 5A) and Jurkat cells (Figure 5B) with TQ induced a dose-dependent decrease in the protein level expression of Bcl-2, starting at $300 \mu \mathrm{M}$ TQ in HCT-116 cells (Figure 5A) and at $10 \mu \mathrm{M}$ in Jurkat cells (Figure 5B). A kinetic analysis of TQ was then conducted on Bcl-2 expression in HCT-116 cells, using $400 \mu \mathrm{M}$ TQ (Figure 5C) and $200 \mu \mathrm{M}$ TQ in Jurkat cells (Figure 5D), concentrations at which Bcl-2 became undetectable after $24 \mathrm{~h}$ of treatment in HCT-116 cells (Figure 5A) and Jurkat cells (Figure 5B). The time-course effects on Bcl-2 expression showed that TQ induced a decrease in the expression of Bcl-2 beginning at $1 \mathrm{~h}$ in HCT-116 cells (Figure 5C) and at $30 \mathrm{~min}$ in Jurkat cells (Figure 5D). However, Western blot analysis revealed no high-molecular-weight bands of Bcl-2 in TQ-treated HCT-116 cells (Figure 5C) or Jurkat cells (Figure 5D), indicating that, unlike its effects on UHRF1, TQ did not induce the fast ubiquitination of Bcl-2 in cancer cells. 
A

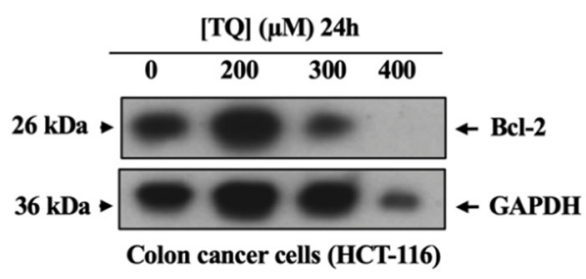

C

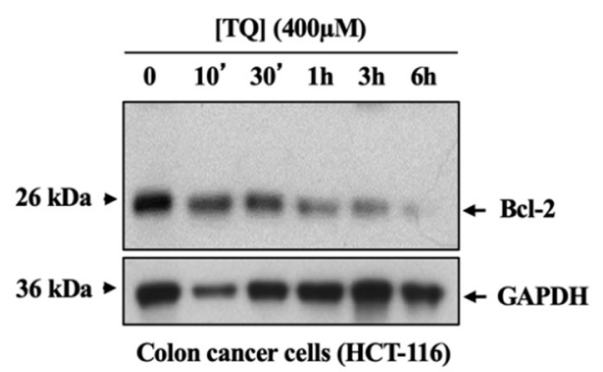

B

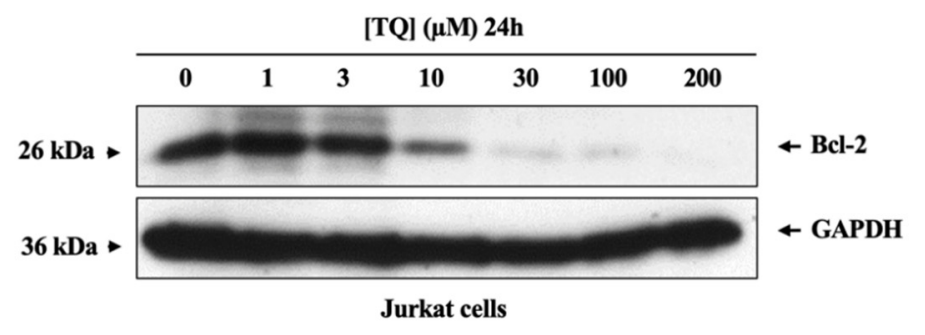

D

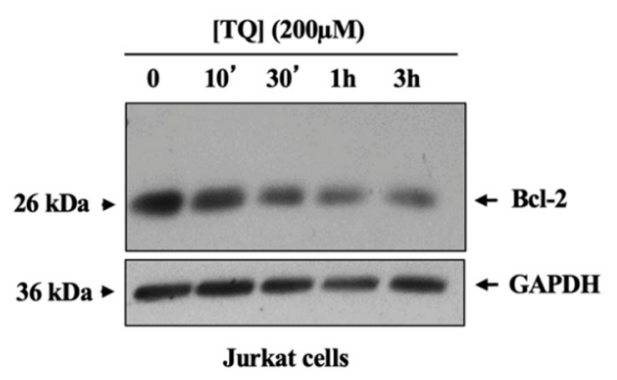

Figure 5. Dose- and time-dependent effects of TQ on the protein expression of Bcl-2 in cancer cells. HCT-116 cells were exposed to increasing concentrations of TQ for $24 \mathrm{~h}$ (A) or exposed to $400 \mu \mathrm{M}$ TQ for different times (C). Jurkat cells were exposed to increasing concentrations of TQ for $24 \mathrm{~h}$ (B) or exposed to $200 \mu \mathrm{M}$ TQ for different times (D). Expres-sion of Bcl-2 was analyzed via Western blotting, as described in the Materials and Methods.

\section{Discussion}

The overexpression of UHRF1, detected in many solid and hematological tumors, is known to inhibit the expression of various tumor suppressor genes (TSGs) and to inhibit apoptosis $[4,7,17]$. Several studies have shown that natural anticancer compounds, including TQ, can decrease UHRF1 expression in cancer cells and reactivate silenced TSGs with the subsequent induction of apoptosis $[1,4,5,11,17,44]$. Recently, TQ was shown to induce the fast auto-polyubiquitination of UHRF1 through its RING domain, and this effect was correlated with a decrease in the expression of the HAUSP deubiquitinase [11]. In the present study, two natural compounds-TQ and doxorubicin, which exhibit anticancer properties on various cancer cells through the targeting of several signaling pathwayswere evaluated for their effects on UHRF1 expression in colon cancer cells and Jurkat cells. The kinetic effects of TQ on UHRF1 expression in colon cancer and Jurkat cells showed that UHRF1 was ubiquitinated, as reflected by the appearance of high-molecular-weight bands, and this effect was associated with a downregulation of HAUSP. Like the TQ effects, doxorubicin also induced a dose-dependent degradation of UHRF1 in colon cancer cells and Jurkat cells. However, the kinetic effect of doxorubicin on UHRF1 expression did not show the appearance of any high-molecular-weight bands of UHRF1 in either of the cancer cell lines, suggesting that UHRF1 ubiquitination in cancer cells is triggered only by TQ, and not by doxorubicin.

The present findings support the presence of a strong correlation between the TQinduced ubiquitination of UHRF1 and its subsequent degradation in cancer cells [11]. In the present study, the time-course effects of doxorubicin on UHRF1 expression in colon cancer cells and Jurkat cells did not reveal any high-molecular-weight bands in either cancer cell line. This suggests that the degradation of UHRF1 in response to TQ requires auto-ubiquitination through its RING domain, but this step is not required in the response to other natural compounds that exhibit anticancer activities. This process could involve, in part, the downregulation of HAUSP to allow the auto-ubiquitination of UHRF1 and its degradation, followed by the subsequent upregulation of TSGs, the inhibition of cell 
proliferation and the induction of apoptosis. Indeed, several natural products, including naphthazarin [19], shikonin [20], curcumin [5], EGCG [4], resveratrol [21] and luteolin [22], as well as TQ [1,25], have been shown to decrease the expression of UHRF1 in cancer cells, but their underlying molecular mechanisms are largely unknown. Few studies have conducted kinetic analyses of the effects of these natural products on UHRF1 expression. The time-course effects of Antho 50, an anthocyanin-rich dietary bilberry extract, on UHRF1 expression in cells from patients with B-cell chronic lymphocytic leukemia (B CLL) showed a progressive decrease in UHRF1 expression, but without the appearance of high-molecular-weight bands of UHRF1 [45]. In the present study, the time-course effects of TQ on UHRF1 in colon cancer, as a model of solid tumors, and in Jurkat cells, as a hematological tumor model, revealed that TQ induced the appearance of high-molecularweight bands of UHRF1, but doxorubicin did not. This finding suggests that TQ can induce UHRF1 ubiquitination in cancer cells as an indispensable event that triggers the onset of apoptosis, and this process could be as a result of the disassociation between HAUSP and UHRF1. Considering that TQ has no or minimal effects on normal human cells $[24,46]$ and that UHRF1 is overexpressed in several tumors, TQ could be a promising specific regulator of the HAUSP/UHRF1 axis that functions by inducing UHRF1 ubiquitination.

Several studies in various cancer cells have shown that TQ induces a downregulation of the Bcl-2 oncogene [47-52], one of the master activators of the anti-apoptotic effects in cancer. In the present study, we found that TQ induces a dose- and time-dependent downregulation of Bcl-2 in colon cancer cells. However, it apparently does not do so by inducing ubiquitination, based on the lack of high-molecular-weight bands of Bcl-2. Therefore, TQ can induce a fast ubiquitination of UHRF1 but apparently not of other oncogenes such as Bcl-2, and this ubiquitination is indispensable for UHRF1 degradation. Bcl-2 is degraded via the activation of the proteasome ubiquitination pathway in response to the natural product pseudolaric acid B [43], whereas TQ is suggested to induce Bcl2 degradation in cancer cells through an ubiquitination-independent mechanism. In agreement with this hypothesis, TQ induced a time-dependent downregulation of Bcl-2 in human multiple myeloma cells through the inhibition of STAT3 [52], which is a main regulator of Bcl-2 [53,54].

TQ, by virtue of its ability to induce the early ubiquitination of the oncogene UHRF1, followed by its degradation in both Jurkat cells as an experimental model of hematological malignancy as well as colon cancer as a model of solid tumors, the present study supports the chemopreventive and therapeutic potential of TQ for both human blood and solid tumors. However, due to its highly lipophilic nature, poor aqueous solubility and inadequate biological stability, TQ is characterized by poor bioavailability. However, many approaches to address TQ's pharmacokinetic limitations, such as formulations of TQ in lipid nanocarriers, are currently being developed [55,56].

In conclusion, the present study shows that, unlike the anticancer drug doxorubicin, TQ can trigger the fast ubiquitination of UHRF1, but not of another oncogene, Bcl-2. The underlying mechanism could involve the downregulation of HAUSP, which normally would protect UHRF1 from ubiquitination (see the Graphical Abstract). Nevertheless, the profound mechanisms of TQ's effects on the ubiquitination status of UHRF1 still require further investigation. Objectively, due to the underlying complexity of the mechanisms of the interaction between UHRF1 and several proteins, including HAUSP [57], further studies are needed to explore the detailed mechanisms by which UHRF1 is rapidly polyubiquitinated in cancer cells in response to TQ and how HAUSP could be involved in the process.

Author Contributions: Conceptualization, M.A., O.A. and Z.O.; methodology, M.A. and A.K.; validation, M.A and Z.O.; formal analysis, M.A.; investigation, A.K.; writing-original draft preparation, M.A. and A.K.; writing-review and editing, M.A. and O.A.; funding acquisition, O.A and Z.O. All authors have read and agreed to the published version of the manuscript. 
Funding: This research was funded by the deanship of Scientific Research at Umm Al-Qura University, grant number 19-MED-1-02-0008.

Institutional Review Board Statement: Not applicable.

Informed Consent Statement: Not applicable.

Data Availability Statement: All data generated or analyzed during this study are included in this published article or are available from the corresponding authors on reasonable request.

Acknowledgments: The authors would like to thank the deanship of Scientific Research at Umm Al-Qura University for supporting this work by Grant Code: 19-MED-1-02-0008.

Conflicts of Interest: The authors declare that they have no competing interests.

\section{References}

1. Alhosin, M.; Abusnina, A.; Achour, M.; Sharif, T.; Muller, C.; Peluso, J.; Chataigneau, T.; Lugnier, C.; Schini-Kerth, V.B.; Bronner, C.; et al. Induction of apoptosis by thymoquinone in lymphoblastic leukemia Jurkat cells is mediated by a p73-dependent pathway which targets the epigenetic integrator UHRF1. Biochem. Pharmacol. 2010, 79, 1251-1260. [CrossRef]

2. Bronner, C.; Krifa, M.; Mousli, M. Increasing role of UHRF1 in the reading and inheritance of the epigenetic code as well as in tumorogenesis. Biochem. Pharmacol. 2013, 86, 1643-1649. [CrossRef]

3. Zaayter, L.; Mori, M.; Ahmad, T.; Ashraf, W.; Boudier, C.; Kilin, V.; Gavvala, K.; Richert, L.; Eiler, S.; Ruff, M.; et al. A Molecular Tool Targeting the Base-Flipping Activity of Human UHRF1. Chemistry 2019, 25, 13363-13375. [CrossRef]

4. Achour, M.; Mousli, M.; Alhosin, M.; Ibrahim, A.; Peluso, J.; Muller, C.D.; Schini-Kerth, V.B.; Hamiche, A.; Dhe-Paganon, S.; Bronner, C. Epigallocatechin-3-gallate up-regulates tumor suppressor gene expression via a reactive oxygen species-dependent down-regulation of UHRF1. Biochem. Biophys. Res. Commun. 2013, 430, 208-212. [CrossRef]

5. Abusnina, A.; Keravis, T.; Yougbaré, I.; Bronner, C.; Lugnier, C. Anti-proliferative effect of curcumin on melanoma cells is mediated by PDE1A inhibition that regulates the epigenetic integrator UHRF1. Mol. Nutr. Food Res. 2011, 55, 1677-1689. [CrossRef]

6. Qadi, S.A.; Hassan, M.A.; Sheikh, R.A.; Baothman, O.A.; Zamzami, M.A.; Choudhry, H.; Al-Malki, A.L.; Albukhari, A.; Alhosin, M. Thymoquinone-Induced Reactivation of Tumor Suppressor Genes in Cancer Cells Involves Epigenetic Mechanisms. Epigenetics Insights 2019, 12. [CrossRef]

7. Alhosin, M.; Sharif, T.; Mousli, M.; Etienne-Selloum, N.; Fuhrmann, G.; Schini-Kerth, V.B.; Bronner, C. Down-regulation of UHRF1, associated with re-expression of tumor suppressor genes, is a common feature of natural compounds exhibiting anti-cancer properties. J. Exp. Clin. Cancer Res. CR 2011, 30, 41. [CrossRef] [PubMed]

8. Jenkins, Y.; Markovtsov, V.; Lang, W.; Sharma, P.; Pearsall, D.; Warner, J.; Franci, C.; Huang, B.; Huang, J.; Yam, G.C.; et al. Critical role of the ubiquitin ligase activity of UHRF1, a nuclear RING finger protein, in tumor cell growth. Mol. Biol. Cell 2005, 16, 5621-5629. [CrossRef] [PubMed]

9. Citterio, E.; Papait, R.; Nicassio, F.; Vecchi, M.; Gomiero, P.; Mantovani, R.; Di Fiore, P.P.; Bonapace, I.M. Np95 is a histone-binding protein endowed with ubiquitin ligase activity. Mol. Cell. Biol. 2004, 24, 2526-2535. [CrossRef]

10. Karagianni, P.; Amazit, L.; Qin, J.; Wong, J. ICBP90, a novel methyl K9 H3 binding protein linking protein ubiquitination with heterochromatin formation. Mol. Cell. Biol. 2008, 28, 705-717. [CrossRef] [PubMed]

11. Ibrahim, A.; Alhosin, M.; Papin, C.; Ouararhni, K.; Omran, Z.; Zamzami, M.A.; Al-Malki, A.L.; Choudhry, H.; Mély, Y.; Hamiche, A.; et al. Thymoquinone challenges UHRF1 to commit auto-ubiquitination: A key event for apoptosis induction in cancer cells. Oncotarget 2018, 9, 28599-28611. [CrossRef] [PubMed]

12. Li, M.; Brooks, C.L.; Kon, N.; Gu, W. A dynamic role of HAUSP in the p53-Mdm2 pathway. Mol. Cell 2004, 13, 879-886. [CrossRef]

13. Canning, M.; Boutell, C.; Parkinson, J.; Everett, R.D. A RING finger ubiquitin ligase is protected from autocatalyzed ubiquitination and degradation by binding to ubiquitin-specific protease USP7. J. Biol. Chem. 2004, 279, 38160-38168. [CrossRef] [PubMed]

14. Oh, Y.M.; Yoo, S.J.; Seol, J.H. Deubiquitination of Chfr, a checkpoint protein, by USP7/HAUSP regulates its stability and activity. Biochem. Biophys. Res. Commun. 2007, 357, 615-619. [CrossRef] [PubMed]

15. Felle, M.; Joppien, S.; Németh, A.; Diermeier, S.; Thalhammer, V.; Dobner, T.; Kremmer, E.; Kappler, R.; Längst, G. The USP7/Dnmt1 complex stimulates the DNA methylation activity of Dnmt1 and regulates the stability of UHRF1. Nucleic Acids Res. 2011, 39, 8355-8365. [CrossRef] [PubMed]

16. Xia, T.; Liu, S.; Xu, G.; Zhou, S.; Luo, Z. Dihydroartemisinin induces cell apoptosis through repression of UHRF1 in prostate cancer cells. Anticancer Drugs 2021. [CrossRef]

17. Alhosin, M.; Omran, Z.; Zamzami, M.A.; Al-Malki, A.L.; Choudhry, H.; Mousli, M.; Bronner, C. Signalling pathways in UHRF1-dependent regulation of tumor suppressor genes in cancer. J. Exp. Clin. Cancer Res. CR 2016, 35, 174. [CrossRef]

18. Unoki, M. Current and potential anticancer drugs targeting members of the UHRF1 complex including epigenetic modifiers. Recent Pat. Anti-Cancer Drug Discov. 2011, 6, 116-130. [CrossRef]

19. Kim, M.Y.; Park, S.J.; Shim, J.W.; Yang, K.; Kang, H.S.; Heo, K. Naphthazarin enhances ionizing radiation-induced cell cycle arrest and apoptosis in human breast cancer cells. Int. J. Oncol. 2015, 46, 1659-1666. [CrossRef] 
20. Jang, S.Y.; Hong, D.; Jeong, S.Y.; Kim, J.H. Shikonin causes apoptosis by up-regulating p73 and down-regulating ICBP90 in human cancer cells. Biochem. Biophys. Res. Commun. 2015, 465, 71-76. [CrossRef]

21. Parashar, G.; Capalash, N. Promoter methylation-independent reactivation of PAX1 by curcumin and resveratrol is mediated by UHRF1. Clin. Exp. Med. 2016, 16, 471-478. [CrossRef]

22. Krifa, M.; Leloup, L.; Ghedira, K.; Mousli, M.; Chekir-Ghedira, L. Luteolin induces apoptosis in BE colorectal cancer cells by downregulating calpain, UHRF1, and DNMT1 expressions. Nutr. Cancer 2014, 66, 1220-1227. [CrossRef]

23. Arima, Y.; Hirota, T.; Bronner, C.; Mousli, M.; Fujiwara, T.; Niwa, S.; Ishikawa, H.; Saya, H. Down-regulation of nuclear protein ICBP90 by p53/p21Cip1/WAF1-dependent DNA-damage checkpoint signals contributes to cell cycle arrest at G1/S transition. Genes Cells Devoted Mol. Cell. Mech. 2004, 9, 131-142. [CrossRef]

24. Alhosin, M.; Ibrahim, A.; Boukhari, A.; Sharif, T.; Gies, J.P.; Auger, C.; Schini-Kerth, V.B. Anti-neoplastic agent thymoquinone induces degradation of alpha and beta tubulin proteins in human cancer cells without affecting their level in normal human fibroblasts. Investig. New Drugs 2012, 30, 1813-1819. [CrossRef]

25. Abusnina, A.; Alhosin, M.; Keravis, T.; Muller, C.D.; Fuhrmann, G.; Bronner, C.; Lugnier, C. Down-regulation of cyclic nucleotide phosphodiesterase PDE1A is the key event of p73 and UHRF1 deregulation in thymoquinone-induced acute lymphoblastic leukemia cell apoptosis. Cell. Signal. 2011, 23, 152-160. [CrossRef]

26. Hopfner, R.; Mousli, M.; Jeltsch, J.M.; Voulgaris, A.; Lutz, Y.; Marin, C.; Bellocq, J.P.; Oudet, P.; Bronner, C. ICBP90, a novel human CCAAT binding protein, involved in the regulation of topoisomerase IIalpha expression. Cancer Res. 2000, 60, 121-128. [PubMed]

27. Bronner, C. Control of DNMT1 abundance in epigenetic inheritance by acetylation, ubiquitylation, and the histone code. Sci. Signal. 2011, 4, pe3. [CrossRef] [PubMed]

28. Kofunato, Y.; Kumamoto, K.; Saitou, K.; Hayase, S.; Okayama, H.; Miyamoto, K.; Sato, Y.; Katakura, K.; Nakamura, I.; Ohki, S.; et al. UHRF1 expression is upregulated and associated with cellular proliferation in colorectal cancer. Oncol. Rep. 2012, 28, 1997-2002. [CrossRef] [PubMed]

29. Wang, F.; Yang, Y.Z.; Shi, C.Z.; Zhang, P.; Moyer, M.P.; Zhang, H.Z.; Zou, Y.; Qin, H.L. UHRF1 promotes cell growth and metastasis through repression of p16(ink(4)a) in colorectal cancer. Ann. Surg. Oncol. 2012, 19, 2753-2762. [CrossRef] [PubMed]

30. Abbady, A.Q.; Bronner, C.; Trotzier, M.A.; Hopfner, R.; Bathami, K.; Muller, C.D.; Jeanblanc, M.; Mousli, M. ICBP90 expression is downregulated in apoptosis-induced Jurkat cells. Ann. N. Y. Acad. Sci. 2003, 1010, 300-303. [CrossRef] [PubMed]

31. Yu, C.; Xing, F.; Tang, Z.; Bronner, C.; Lu, X.; Di, J.; Zeng, S.; Liu, J. Anisomycin suppresses Jurkat T cell growth by the cell cycle-regulating proteins. Pharmacol. Rep. PR 2013, 65, 435-444. [CrossRef]

32. Mandili, G.; Khadjavi, A.; Gallo, V.; Minero, V.G.; Bessone, L.; Carta, F.; Giribaldi, G.; Turrini, F. Characterization of the protein ubiquitination response induced by Doxorubicin. FEBS J. 2012, 279, 2182-2191. [CrossRef] [PubMed]

33. Halim, V.A.; García-Santisteban, I.; Warmerdam, D.O.; van den Broek, B.; Heck, A.J.R.; Mohammed, S.; Medema, R.H. Doxorubicininduced DNA Damage Causes Extensive Ubiquitination of Ribosomal Proteins Associated with a Decrease in Protein Translation. Mol. Cell. Proteom. MCP 2018, 17, 2297-2308. [CrossRef]

34. Lang, V.; Aillet, F.; Xolalpa, W.; Serna, S.; Ceccato, L.; Lopez-Reyes, R.G.; Lopez-Mato, M.P.; Januchowski, R.; Reichardt, N.C.; Rodriguez, M.S. Analysis of defective protein ubiquitylation associated to adriamycin resistant cells. Cell Cycle 2017, 16, 2337-2344. [CrossRef]

35. Yuan, L.; Tian, J. LIN28B promotes the progression of colon cancer by increasing B-cell lymphoma 2 expression. Biomed. Pharmacother. Biomed. Pharmacother. 2018, 103, 355-361. [CrossRef] [PubMed]

36. Sun, N.; Meng, Q.; Tian, A. Expressions of the anti-apoptotic genes Bag-1 and Bcl-2 in colon cancer and their relationship. Am. J. Surg. 2010, 200, 341-345. [CrossRef] [PubMed]

37. Meterissian, S.H.; Kontogiannea, M.; Al-Sowaidi, M.; Linjawi, A.; Halwani, F.; Jamison, B.; Edwardes, M. Bcl-2 is a useful prognostic marker in Dukes' B colon cancer. Ann. Surg. Oncol. 2001, 8, 533-537. [CrossRef] [PubMed]

38. Paul-Samojedny, M.; Kokocińska, D.; Samojedny, A.; Mazurek, U.; Partyka, R.; Lorenz, Z.; Wilczok, T. Expression of cell survival/death genes: Bcl-2 and Bax at the rate of colon cancer prognosis. Biochim. Et Biophys. Acta 2005, 1741, 25-29. [CrossRef]

39. Kleschyov, A.L.; Strand, S.; Schmitt, S.; Gottfried, D.; Skatchkov, M.; Sjakste, N.; Daiber, A.; Umansky, V.; Munzel, T. Dinitrosyl-iron triggers apoptosis in Jurkat cells despite overexpression of Bcl-2. Free Radic. Biol. Med. 2006, 40, 1340-1348. [CrossRef]

40. Thomson, S.J.; Brown, K.K.; Pullar, J.M.; Hampton, M.B. Phenethyl isothiocyanate triggers apoptosis in Jurkat cells made resistant by the overexpression of Bcl-2. Cancer Res. 2006, 66, 6772-6777. [CrossRef]

41. Molto, L.; Rayman, P.; Paszkiewicz-Kozik, E.; Thornton, M.; Reese, L.; Thomas, J.C.; Das, T.; Kudo, D.; Bukowski, R.; Finke, J.; et al. The Bcl-2 transgene protects T cells from renal cell carcinoma-mediated apoptosis. Clin. Cancer Res. 2003, 9, $4060-4068$.

42. Breitschopf, K.; Haendeler, J.; Malchow, P.; Zeiher, A.M.; Dimmeler, S. Posttranslational modification of Bcl-2 facilitates its proteasome-dependent degradation: Molecular characterization of the involved signaling pathway. Mol. Cell. Biol. 2000, 20, 1886-1896. [CrossRef] [PubMed]

43. Zhao, D.; Lin, F.; Wu, X.; Zhao, Q.; Zhao, B.; Lin, P.; Zhang, Y.; Yu, X. Pseudolaric acid B induces apoptosis via proteasomemediated Bcl-2 degradation in hormone-refractory prostate cancer DU145 cells. Toxicol. Vitr. 2012, 26, 595-602. [CrossRef] [PubMed]

44. Sidhu, H.; Capalash, N. UHRF1: The key regulator of epigenetics and molecular target for cancer therapeutics. Tumour Biol. 2017, 39. [CrossRef] [PubMed] 
45. Alhosin, M.; Leon-Gonzalez, A.J.; Dandache, I.; Lelay, A.; Rashid, S.K.; Kevers, C.; Pincemail, J.; Fornecker, L.M.; Mauvieux, L.; Herbrecht, R.; et al. Bilberry extract (Antho 50) selectively induces redox-sensitive caspase 3-related apoptosis in chronic lymphocytic leukemia cells by targeting the Bcl-2/Bad pathway. Sci. Rep. 2015, 5, 8996. [CrossRef]

46. Sutton, K.M.; Greenshields, A.L.; Hoskin, D.W. Thymoquinone, a bioactive component of black caraway seeds, causes G1 phase cell cycle arrest and apoptosis in triple-negative breast cancer cells with mutant p53. Nutr. Cancer 2014, 66, 408-418. [CrossRef] [PubMed]

47. Liu, X.; Dong, J.; Cai, W.; Pan, Y.; Li, R.; Li, B. The Effect of Thymoquinone on Apoptosis of SK-OV-3 Ovarian Cancer Cell by Regulation of Bcl-2 and Bax. Int. J. Gynecol. Cancer 2017, 27, 1596-1601. [CrossRef]

48. Park, E.J.; Chauhan, A.K.; Min, K.J.; Park, D.C.; Kwon, T.K. Thymoquinone induces apoptosis through downregulation of c-FLIP and Bcl-2 in renal carcinoma Caki cells. Oncol. Rep. 2016, 36, 2261-2267. [CrossRef]

49. Badr, G.; Mohany, M.; Abu-Tarboush, F. Thymoquinone decreases F-actin polymerization and the proliferation of human multiple myeloma cells by suppressing STAT3 phosphorylation and Bcl2/Bcl-XL expression. Lipids Health Dis. 2011, 10, 236. [CrossRef]

50. Samarghandian, S.; Azimi-Nezhad, M.; Farkhondeh, T. Thymoquinone-induced antitumor and apoptosis in human lung adenocarcinoma cells. J. Cell. Physiol. 2019, 234, 10421-10431. [CrossRef]

51. Ng, W.K.; Yazan, L.S.; Ismail, M. Thymoquinone from Nigella sativa was more potent than cisplatin in eliminating of SiHa cells via apoptosis with down-regulation of Bcl-2 protein. Toxicol. Vitr. 2011, 25, 1392-1398. [CrossRef] [PubMed]

52. Li, F.; Rajendran, P.; Sethi, G. Thymoquinone inhibits proliferation, induces apoptosis and chemosensitizes human multiple myeloma cells through suppression of signal transducer and activator of transcription 3 activation pathway. Br. J. Pharmacol. 2010, 161, 541-554. [CrossRef] [PubMed]

53. Costantino, L.; Barlocco, D. STAT 3 as a target for cancer drug discovery. Curr. Med. Chem. 2008, 15, 834-843. [CrossRef]

54. Zhao, X.; Guo, X.; Shen, J.; Hua, D. Alpinetin inhibits proliferation and migration of ovarian cancer cells via suppression of STAT3 signaling. Mol. Med. Rep. 2018, 18, 4030-4036. [CrossRef] [PubMed]

55. Mohammadabadi, M.R.; Mozafari, M.R. Enhanced efficacy and bioavailability of thymoquinone using nanoliposomal dosage form. J. Drug Deliv. Sci. Technol. 2018, 47, 445-453. [CrossRef]

56. Pal, R.R.; Rajpal, V.; Singh, P.; Saraf, S.A. Recent Findings on Thymoquinone and Its Applications as a Nanocarrier for the Treatment of Cancer and Rheumatoid Arthritis. Pharmaceutics 2021, 13, 775. [CrossRef]

57. Abdullah, O.; Omran, Z.; Hosawi, S.; Hamiche, A.; Bronner, C.; Alhosin, M. Thymoquinone Is a Multitarget Single Epidrug That Inhibits the UHRF1 Protein Complex. Genes 2021, 12, 622. [CrossRef] 